A $\mathrm{C} G$ Rec. Nat. Prod. 16:4 (2022) 324-334

records of natural products

\title{
Monoester-Type C19-Diterpenoid Alkaloids from Aconitum carmichaelii and Their Cardiotoxicity
}

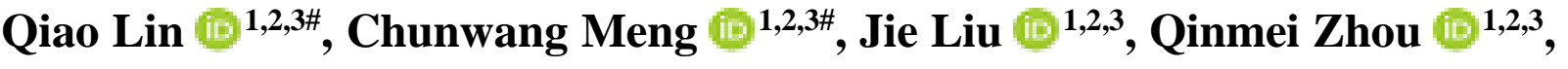

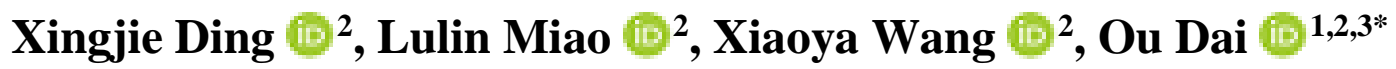 \\ and Cheng Peng ${ }^{1}$ 1,* $^{*}$
}

\author{
${ }^{1}$ State Key Laboratory of Southwestern Chinese Medicine Resources, Chengdu University of \\ Traditional Chinese Medicine, Chengdu 611137, P. R. China \\ ${ }^{2}$ School of Pharmacy, Chengdu University of Traditional Chinese Medicine, Chengdu 611137, P. R. \\ China \\ ${ }^{3}$ Innovative Medicine Ingredients of Southwest Specialty Medicinal Materials, Chengdu University of \\ Traditional Chinese Medicine, Chengdu 611137, P. R. China
}

(Received July 08, 2021; Revised September 20, 2021; Accepted September 21, 2021)

\begin{abstract}
A new (1) and six known (2-7) monoester-type $\mathrm{C}_{19}$-diterpenoid alkaloids were isolated from the lateral roots of Aconitum carmichaelii Debx. Their structures were determined by spectroscopic techniques and calculations of NMR chemical shifts. Compound 1 (1-epi-hokbusine A) was an aconitine-type diterpenoid alkaloid possessing an unusual $1 \beta$-methoxy group. According to the main toxicity of the lateral roots of $A$. carmichaelii, the cardiotoxic effects of the isolates were evaluated using $\mathrm{H} 9 \mathrm{c} 2$ rat myocardial cells and zebrafish embryos. The results showed that all the monoester-type $\mathrm{C}_{19}$-diterpenoid alkaloids exhibited cardiotoxicity, and compound 6 was found to be the most toxic compound.
\end{abstract}

Keywords: Aconitum carmichaelii; monoester-type $\mathrm{C}_{19}$-diterpenoid alkaloids; H9c2 cells; zebrafish embryos; cardiotoxicity. (C) 2021 ACG Publications. All rights reserved.

\section{Introduction}

The lateral roots of Aconitum carmichaelii Debx. (Ranunculaceae), named Fuzi in Chinese, were first documented in Shennong's Materia Medica (Shennong Bencao Jing in Chinese) approximately 2000 years ago and have been widely used in China [1-2]. In modern clinical applications, Fuzi is extensively used to treat heart failure, but it has great cardiotoxicity, including tachycardia, atrioventricular block, cardiogenic shock, and cardiac arrest [3-6]. Thus, the remarkable cardiotoxicity of Fuzi has attracted more and more attentions. $\mathrm{C}_{19}$-diterpenoid alkaloids are confirmed as the main effective and toxic constituents of Fuzi and can be divided into three categories (diestertype, monoester-type, and aminoalcohol-type) based on the number of ester bonds. Diester-type $\mathrm{C}_{19}$ diterpenoid alkaloids have a stronger cardiotoxicity than monoester-type $\mathrm{C}_{19}$-diterpenoid alkaloids,

\footnotetext{
*Corresponding author: E-Mail: oudai1123@hotmail.com (O. Dai); pengcheng@cdutcm.edu.cn (C. Peng).
} 
followed by aminoalcohol-type $\mathrm{C}_{19}$-diterpenoid alkaloids [4,7]. As for the aminoalcohol-type $\mathrm{C}_{19}$ diterpenoid alkaloids, researchers have mainly focused on their cardiotonic or cardioprotective effects [8,9]. In our previous studies, 14 aminoalcohol-diterpenoid alkaloids with cardioprotective effects were isolated from Fuzi, and their concentration-response and rudimentary structure-activity relationships were also investigated [10]. On the contrary, the diester-type $\mathrm{C}_{19}$-diterpenoid alkaloids are believed to be the principal cardiotoxic substances of Fuzi. Especially, some representative alkaloids, such as aconitine, mesaconitine, and hypaconitine, have been intensively researched [1113]. However, few studies have looked at the cardiotoxicity of the monoester-type $\mathrm{C}_{19}$-diterpenoid alkaloids [14]. Thus, this study performed a phytochemical investigation on the monoester-type $\mathrm{C}_{19}$ diterpenoid alkaloids of Fuzi and explored their cardiotoxicity. Seven monoester-type $\mathrm{C}_{19}$-diterpenoid alkaloids (1-7) (Figure 1) with cardiotoxicity were isolated, including an aconitine-type alkaloid possessing an unusual $1 \beta$-methoxy group (1).
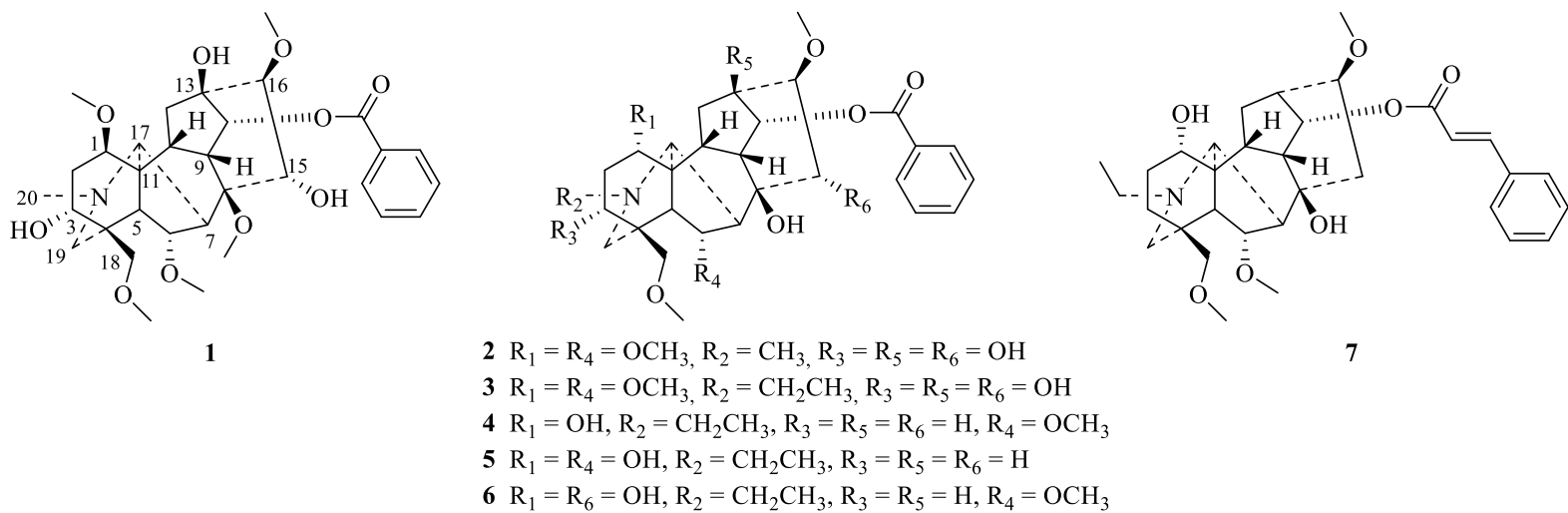

Figure 1. Structures of compounds 1-7

\section{Materials and Methods}

\subsection{General experimental procedures}

Anton Paar MCP 200 automatic polarimeter (Anton Paar GmbH, Austria) was used to detect the optical rotations. IR spectra were measured on an Agilent cary 600 FT-IR microscope instrument (Agilent Technologies Inc., CA, USA). Agilent 1260-MTQ-2 instrument (Agilent Technologies Inc., CA, USA) was applied to record HRESIMS spectra. NMR spectra were taken by a Bruker-AvanceNeo-600 spectrometer (Bruker Corporation, Billerica, MA, USA) using solvent peaks as references. TLC was conducted by silica gel GF254 plates (Qingdao Marine Chemical Inc., Qingdao, China). Column chromatography was performed using macroporous adsorbent resin (D-101; Anhui Sanxing Resin Technology Co., Ltd., Anhui, China), silica gel (Yantai Institute of Chemical Technology, Yantai, China), and Sephadex LH-20 (Amersham Pharmacia Biotech AB, Uppsala, Sweden). HPLC separations were performed using an Agilent 1100 instrument (Agilent Technologies Inc., CA, USA) equipped with an Ultimate XB-C18 $(250 \times 10 \mathrm{~mm}, 5 \mu \mathrm{m})$. Fetal bovine serum (FBS) was from Cao Yuan Lv Ye Bio-engineering Materials Co., Ltd. (Hohhot, China). 3-(4,5-Dimethylthiazol-2-yl)-2,5diphenyl tetrazolium (MTT) was purchased from Sigma-Aldrich Corporation (St. Louis, Missouri, US). Varioskan advanced multifunctional enzyme marker (Thermo, USA) measured the OD values. Leica M165Fic fluorescence microscope (Leica Microsystems, Germany) was used to observe the morphological changes of zebrafish.

\subsection{Plant Material}

A. carmichaelii were obtained from Sichuan Jiangyou Zhongba Fuzi Technology Development Co., Ltd. (Jiangyou, Sichuan, China and its voucher specimen (SFZ-0710) was deposited in the 
Monoester-type $\mathrm{C}_{19}$-diterpenoid alkaloids

Institute of Innovative Medicine Ingredients of Southwest Specialty Medicinal Materials, Chengdu University of TCM, Sichuan, China [10].

\subsection{Extraction and Isolation}

For extraction and preliminary fractionation of Fuzi, refer to reference [10]. Separation of portion E (12 g) was performed via RP-MPLC eluted by a gradient solvent system $\left(10-100 \% \mathrm{MeOH}\right.$ in $\left.\mathrm{H}_{2} \mathrm{O}\right)$ to get 14 fractions $\left(\mathrm{E}_{1}-\mathrm{E}_{14}\right)$. Fraction $\mathrm{E}_{1}$ was purified by preparative TLC $\left(\mathrm{CH}_{2} \mathrm{Cl}_{2} / \mathrm{MeOH} / \mathrm{NH}_{3} \cdot \mathrm{H}_{2} \mathrm{O}\right.$, 15:1:0.1) and HPLC $\left(\mathrm{MeOH} / \mathrm{H}_{2} \mathrm{O}, 38: 62\right)$ to afford compound $6(3.1 \mathrm{mg}) . \mathrm{E}_{2-1}-\mathrm{E}_{2-6}$ were afforded by chromatographing $\mathrm{E}_{2}$ over Sephadex LH-20 column chromatography (petroleum ether/ $\mathrm{CH}_{2} \mathrm{Cl}_{2} / \mathrm{MeOH}$, 2:2:1). Successive purification of subfraction $\mathrm{E}_{2-6}$ by TLC $\left(\mathrm{CH}_{2} \mathrm{Cl}_{2} / \mathrm{MeOH} / \mathrm{NH}_{3} \cdot \mathrm{H}_{2} \mathrm{O}, 10: 1: 0.1\right)$ and RP HPLC (35\% MeOH in $\mathrm{H}_{2} \mathrm{O}$, containing $0.1 \%$ acetic acid) yielded compound 5 (2.5 mg). Fraction $\mathrm{E}_{3}$ was separated by silica gel column chromatography (petroleum ether $/ \mathrm{Me}_{2} \mathrm{CO} /$ diethylamine, 10:1:0.1 to 3:1:0.1), followed by preparative TLC $\left(\mathrm{CH}_{2} \mathrm{Cl}_{2} / \mathrm{MeOH} / \mathrm{NH}_{3} \cdot \mathrm{H}_{2} \mathrm{O}, 10: 1: 0.1\right)$ to yield compound 2 $(4.2 \mathrm{mg})$. Fraction $\mathrm{E}_{4}$ was further divided into $\mathrm{E}_{4-1}-\mathrm{E}_{4-3}$ by silica gel column chromatography (petroleum ether/Me $\mathrm{Me}_{2} \mathrm{CO} /$ diethylamine, 10:1:0.1 to 3:1:0.1). Purification of subfraction $\mathrm{E}_{4-2}$ by $\mathrm{RP}$ semipreparative $\mathrm{HPLC}$ (44\% $\mathrm{MeCN}$ in $\mathrm{H}_{2} \mathrm{O}$, containing 0.1\% TFA) afforded compound 1 (4.2 mg). Subfraction $\mathrm{E}_{4-3}$ was purified by preparative TLC (petroleum ether/ $\mathrm{Me}_{2} \mathrm{CO} /$ diethylamine, 3:1:0.1) to yield compound $3(3.6 \mathrm{mg})$. Fraction $\mathrm{E}_{7}$ was chromatographed via a Sephadex LH-20 column $\left(\mathrm{CH}_{2} \mathrm{Cl}_{2} / \mathrm{MeOH}\right.$, 1:1) to obtain $\mathrm{E}_{7-1}-\mathrm{E}_{7-4}$. Subfraction $\mathrm{E}_{7-3}$ was further purified by RP-HPLC (20\% $\mathrm{MeCN}$ in $\mathrm{H}_{2} \mathrm{O}$ ) to furnish compounds 4 (6.3 $\mathrm{mg}$ ) and 7 (4.5 $\mathrm{mg}$ ).

\subsection{Spectral Data}

1-epi-Hokbusine $A(\mathbf{1})$ : white powder; $[\alpha]_{\mathrm{D}}^{20}-11.7(c 0.05, \mathrm{MeOH}) ;{ }^{1} \mathrm{H}$ (acetone- $\left.d_{6}, 600 \mathrm{MHz}\right)$ and ${ }^{13} \mathrm{C}$ NMR (acetone- $d_{6}, 150 \mathrm{MHz}$ ) data, see Tables 1 and 2 . IR (ATR) $v_{\max } 3365,2923,1676,1278,1099$, $718 \mathrm{~cm}^{-1}$; (+)-HR-ESI-MS m/z 604.3121 [M + H] ${ }^{+}$(calcd. for $\mathrm{C}_{32} \mathrm{H}_{46} \mathrm{NO}_{10}, 604.3122$ ).

\subsection{Cell culture}

H9c2 cells were cultured in accordance with literature methods [10].

\subsection{Determination of $H 9 c 2$ Cell Viability}

The H9c2 cell viability was assessed by the activity of mitochondrial dehydrogenases using a colorimetric MTT method. Exponentially growing cells were plated into 96 -well plates $\left(7 \times 10^{3}\right.$ cells per well) and incubated for $24 \mathrm{~h}$. Then the cells were treated with the isolated compounds at concentrations of $1.56,3.125,6.25,12.5,25$, and $50 \mu \mathrm{M}$ for $24 \mathrm{~h}$. Then, $0.5 \mathrm{mg} / \mathrm{mL}$ MTT was added into each well. After a 4-hour incubation at $37^{\circ} \mathrm{C}$, the purple formazan crystals were dissolved in 0.18 $\mathrm{mL}$ of DMSO. The optical density ratios were measured on an automated MK3 microplate spectrophotometer (Thermo Fisher Scientific, Waltham, MA, US) at $490 \mathrm{~nm}$.

\subsection{Zebrafish Husbandry}

Zebrafish of wild-type $\mathrm{AB}$ strain obtained from China Zebrafish Resource Center were maintained and raised according to the routine procedures [15]. All zebrafish were kept at $28.5^{\circ} \mathrm{C}$ under a 14-h light/10-h dark cycle. The embryos were generated by natural spawning and maintained in the embryonic medium $(15 \mu \mathrm{M} \mathrm{NaCl}, 500 \mu \mathrm{M} \mathrm{KCl}, 1 \mathrm{mM} \mathrm{CaCl}, 500 \mu \mathrm{M} \mathrm{NaHCO}, 74 \mu \mathrm{M}$ $\mathrm{Na}_{2} \mathrm{HPO}_{4}, 1 \mathrm{mM} \mathrm{MgSO}$, and $120 \mu \mathrm{M} \mathrm{KH}_{2} \mathrm{PO}_{4}$ in distilled $\mathrm{H}_{2} \mathrm{O}$ ). The zebrafish experiments were performed under the approval of the Institutional Animal Care and Use Committee of Chengdu University of Traditional Chinese Medicine. 
Lin et.al., Rec. Nat. Prod. (2022) 16:4 324-334

\subsection{Assessment of Zebrafish Malformation Rates and Heart Rates}

Zebrafish embryos were distributed into 24-well microplates after $48 \mathrm{~h}$ post fertilization (hpf), and at least 15 fish were placed in each well. One well of embryos were treated with $0.1 \%(\mathrm{v} / \mathrm{v})$ DMSO embryo medium (the control group), and other wells were treated with various concentrations of the isolated alkaloids $(6.25,12.5,25$, and $50 \mu \mathrm{M})$. Plates were cultivated at $28.5^{\circ} \mathrm{C}$ for $24 \mathrm{~h}$. The acute toxicity of zebrafish exposed to the isolated alkaloids was determined by observing the changes in zebrafish morphology and examining the malformation rates under a Leica M165Fic fluorescence microscope (Leica Microsystems). At the same time, 60-second video images were collected for mensurable assessment of the heart rates.

\subsection{Data Analysis}

Data analyses were prepared using SPSS 19.0 software (IBM Corp.). Data are shown as the mean \pm standard deviation (SD). Statistical significance was assessed by one-way analysis of variance (ANOVA), followed by a least-significant-difference (LSD) test. Figures were manufactured using GraphPad Prism software Version 5.0 (GraphPad Software, Inc.). In all comparisons, P $<0.05$ indicated a statistically significant difference.

\section{Results and Discussion}

\subsection{Structure Elucidation}

Compound 1 was separated as a white powder possessing a molecular formula of $\mathrm{C}_{32} \mathrm{H}_{45} \mathrm{NO}_{10}$, based on a quasi-molecular ion at $m / z 604.3121[\mathrm{M}+\mathrm{H}]^{+}$(calcd. for $\left.\mathrm{C}_{32} \mathrm{H}_{46} \mathrm{NO}_{10}, 604.3122\right)$ in its HRESIMS. The IR spectrum of 1 showed characteristic absorptions for the carbonyl $\left(1676 \mathrm{~cm}^{-1}\right)$ and $\mathrm{OH}\left(3365 \mathrm{~cm}^{-1}\right)$ functionalities. The ${ }^{1} \mathrm{H}$ NMR spectrum of compound 1 (Table 1) showed signals attributed to five methoxy groups $\left(\delta_{\mathrm{H}} 3.18,3.32,3.37,3.41\right.$, and 3.70$)$, six oxymethine groups $\left[\delta_{\mathrm{H}} 3.42\right.$ $(1 \mathrm{H}, \mathrm{d}, J=6.0 \mathrm{~Hz}, \mathrm{H}-16), 3.71(1 \mathrm{H}, \mathrm{brs}, \mathrm{H}-1), 4.26(1 \mathrm{H}, \mathrm{dd}, J=6.6,1.8 \mathrm{~Hz}, \mathrm{H}-6), 4.29(1 \mathrm{H}, \mathrm{brd}, J=$ $4.2 \mathrm{~Hz}, \mathrm{H}-3), 4.70(1 \mathrm{H}, \mathrm{d}, J=6.0 \mathrm{~Hz}, \mathrm{H}-15)$, and $4.87(1 \mathrm{H}, \mathrm{d}, J=5.4 \mathrm{~Hz}, \mathrm{H}-14)]$, an isolated oxymethylene group $\left[\delta_{\mathrm{H}} 3.43(1 \mathrm{H}\right.$, overlapped, $\mathrm{H}-18 \mathrm{a})$ and $\left.3.59(1 \mathrm{H}, \mathrm{d}, J=7.8 \mathrm{~Hz}, \mathrm{H}-18 \mathrm{~b})\right]$, a $N$ methyl group $\left[\delta_{\mathrm{H}} 3.15\left(3 \mathrm{H}, \mathrm{s}, \mathrm{H}_{3}-20\right)\right]$, an isolated $N$-methylene group $\left[\delta_{\mathrm{H}} 3.45(1 \mathrm{H}, \mathrm{d}, J=12.0 \mathrm{~Hz}, \mathrm{H}-\right.$ 19a) and $3.65(1 \mathrm{H}, \mathrm{d}, J=12.0 \mathrm{~Hz}, \mathrm{H}-19 \mathrm{~b})]$, a characteristic $N$-methine group [ $\left.\delta_{\mathrm{H}} 3.47(1 \mathrm{H}, \mathrm{s}, \mathrm{H}-17)\right]$, and a monosubstituted aromatic ring $\left[\delta_{\mathrm{H}} 7.53\left(2 \mathrm{H}, \mathrm{t}, J=7.8 \mathrm{~Hz}, \mathrm{H}-3^{\prime}\right.\right.$ and $\left.\mathrm{H}-5^{\prime}\right), 7.65(1 \mathrm{H}, \mathrm{m})$, and $8.06\left(2 \mathrm{H}, \mathrm{dd}, J=7.8,1.2 \mathrm{~Hz}, \mathrm{H}-2^{\prime}\right.$ and $\left.\left.\mathrm{H}-6^{\prime}\right)\right]$. The ${ }^{13} \mathrm{C}$ NMR (Table 2) and DEPT data exhibited 32 carbons signals, including six methyls (five oxygenated, $\delta_{\mathrm{C}} 50.3,55.5,59.1,59.3$, and 62.5), four methylenes (one oxygenated, $\delta_{\mathrm{C}} 77.4$ ), 16 methines (six oxygenated, $\delta_{\mathrm{C}} 70.2,76.8,80.0,80.8,82.8$, and 94.5), and six quaternary carbons (two oxygenated, $\delta_{\mathrm{C}} 75.4$ and 83.5; one aromatic, $\delta_{\mathrm{C}} 131.1$; and one carbonylic, $\delta_{\mathrm{C}}$ 166.3). These spectroscopic data revealed that compound 1 was a typical benzoylaconitine-type diterpenoid alkaloid with five methoxy and three hydroxy groups. The planar structure of compound 1 was further confirmed to be the same as hokbusine A [16] by the ${ }^{1} \mathrm{H}-{ }^{1} \mathrm{H}$ COSY and HMBC correlations (Figure 2). However, in comparison with the ${ }^{13} \mathrm{C}$ NMR data of hokbusine A, C-1, C-2, and C-3 in 1 were shielded by $\Delta \delta_{\mathrm{C}}-1.9,-3.7$, and $-1.5 \mathrm{ppm}$, respectively, whereas $\mathrm{C}-17$ and $\mathrm{C}-19$ were deshielded by $\Delta \delta_{\mathrm{C}}+5.3$ and $+2.1 \mathrm{ppm}$. These differences suggested that compound 1 and hokbusine A might be C-1 epimers [16]. In the ROESY spectrum of $\mathbf{1}$, the correlations of H-10 with $\mathrm{H}-6$ and $\mathrm{H}-14$, of $\mathrm{H}-6$ with $\mathrm{H}-9$ and OMe-16, of $\mathrm{H}-15$ with OMe- 8 and $\mathrm{H}-$ 18a, of H-3 with $\mathrm{H}-18 \mathrm{a}$, of $\mathrm{H}-12 \mathrm{~b}$ with $\mathrm{H}-14$; and of $\mathrm{H}-12 \mathrm{a}$ with $\mathrm{H}-1, \mathrm{H}-16$, and $\mathrm{H}-17$, demonstrated that $\mathrm{OH}-3, \mathrm{OH}-15$, and OMe-6 were $\alpha$-oriented, while OMe-1, $\mathrm{H}-14$, and OMe-16 groups were in the $\beta$-orientation. Meanwhile, in the 1D-NOE experiment of 1, irradiation of H-7 enhanced H-15, and irradiation of H-6 enhanced $\mathrm{H}-9$, while irradiation of $\mathrm{H}-12$ a enhanced $\mathrm{H}-1, \mathrm{H}-16$, and $\mathrm{H}-17$. 
These enhancements supported the above configurations. In addition, calculations of NMR chemical shifts were used to further confirm the configuration of C-1. Conformational analyses of $\mathbf{1 a}$ and $\mathbf{1 b}$ (Figure 3) were accomplished via Monte Carlo searching with the MMFF94s molecular mechanics force field by the MOE 2008 software. The conformers were optimized using DFT at the B3LYP/6$31 \mathrm{G}$ (d) level in vacuum with the Gaussian 16 program. The NMR data of $\mathbf{1 a}$ with $1 \beta$-OMe and $\mathbf{1 b}$ with $1 \alpha$-OMe (Figure 3) were calculated at the PCM/mPW1PW91/6-311 + G $(\mathrm{d}, \mathrm{p})$ level by the GIAO method [17]. The calculated ${ }^{13} \mathrm{C}$ NMR chemical shifts of 1a presented a better agreement with the experimental values of $\mathbf{1}$ with a higher correlation coefficient $\left(\mathrm{R}^{2}, \mathbf{1 a}\right.$ : $0.9965 ; \mathbf{1 b}$ : 0.9884 , Figure 4). Furthermore, DP4+ probability analysis [18] based on both ${ }^{1} \mathrm{H}$ and ${ }^{13} \mathrm{C}$ NMR data deduced 1a as the correct configuration with $100 \%$ probability (Supplementary data, Tables S7 and S8). Therefore, the ROESY data, $1 \mathrm{D}-\mathrm{NOE}$ data, and NMR calculations verified that the OMe group at $\mathrm{C}-1$ in compound $\mathbf{1}$ was $\beta$-oriented. Compound 1 was determined to be 1-epi-hokbusine A.

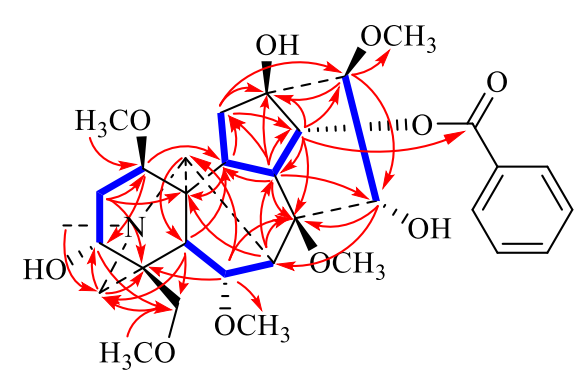

$-{ }^{1} \mathrm{H}-{ }^{1} \mathrm{H}$ COSY

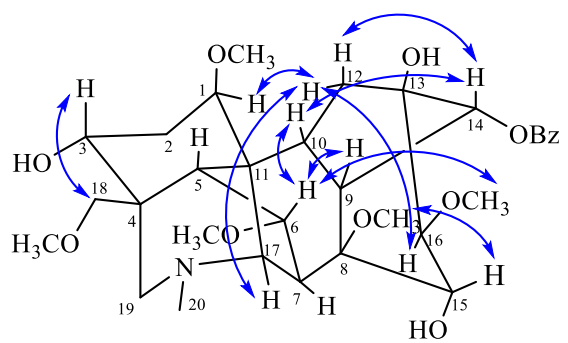

$\mathrm{HMBC}$

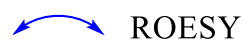

Figure 2. Key ${ }^{1} \mathrm{H}^{-1} \mathrm{H}$ COSY, HMBC, and ROESY correlations of $\mathbf{1}$.

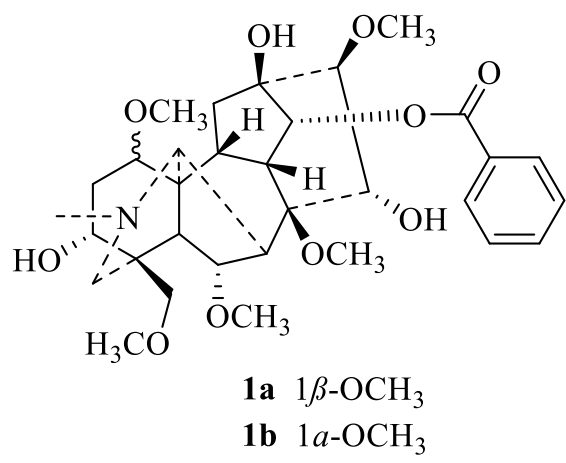

Figure 3. Proposed configurations of $\mathrm{C}-1$ in $\mathbf{1 a}$ and $\mathbf{1 b}$ 
Lin et.al., Rec. Nat. Prod. (2022) 16:4 324-334

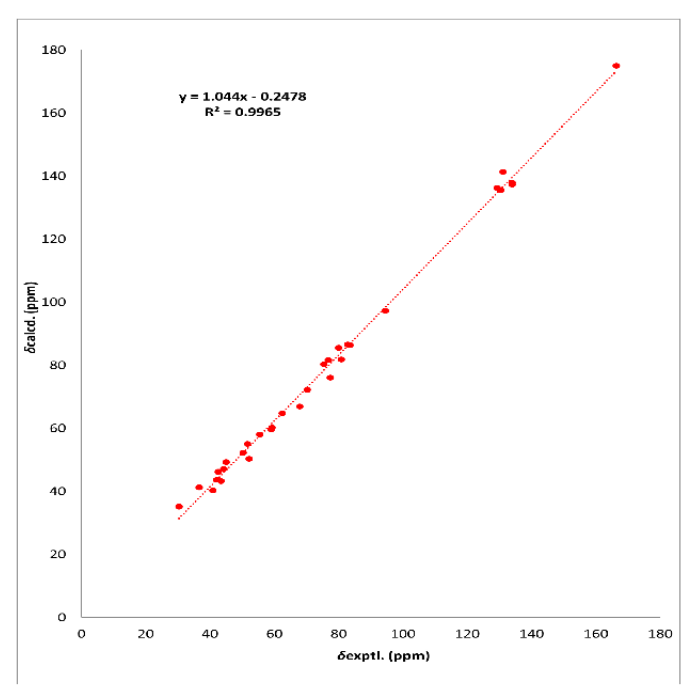

(A) $1 \mathbf{a}$

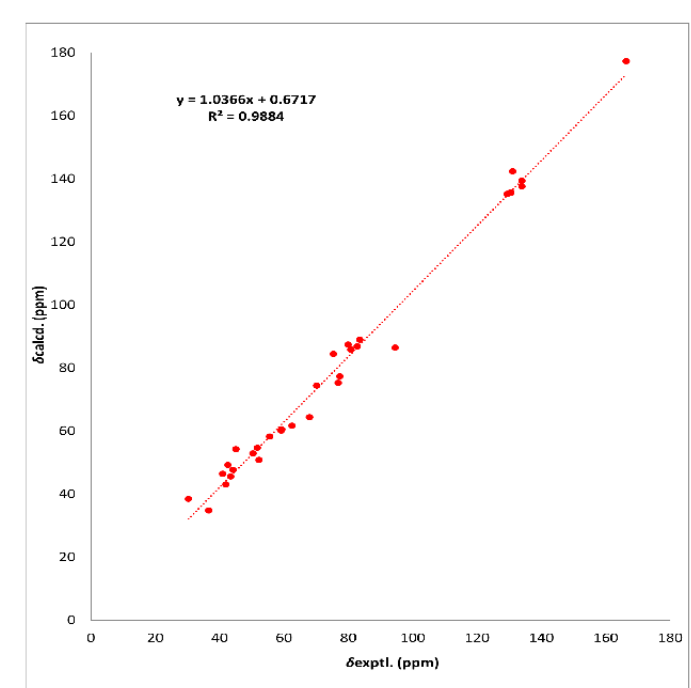

(B) $1 \mathbf{b}$

Figure 4. Correlation plots of experimental ${ }^{13} \mathrm{C}$ NMR chemical shifts versus corresponding calculated ${ }^{13} \mathrm{C}$ NMR chemical shifts for $\mathbf{1 a}(\mathbf{A})$ and $\mathbf{1 b}(\mathbf{B})$.

By comparing the experimental and literature NMR data, six known compounds were identified as 14-benzoylmesaconine (2) [19], 14-benzoylaconine (3) [20], 14-benzoylneoline (4) [21], carmichaenine C (5) [22], (-)-(A-b)-14 $\alpha$-benzoyloxy- $N$-ethyl-1 $\alpha, 8 \beta, 15 \alpha$-trihydroxy- $6 \alpha, 16 \beta, 18$ trimethoxyaconitane (6) [23], and 14-O-cinnamoylneoline (7) [24].

Table 1. ${ }^{1} \mathrm{H}$ NMR data for compound $1(600 \mathrm{MHz})$ and hokbusine A [16]

\begin{tabular}{cccccc}
\hline No. & hokbusine A & $\mathbf{1}$ & No. & hokbusine A & $\mathbf{1}$ \\
\hline 1 & $3.22 \mathrm{brt}(6.4)$ & $3.71 \mathrm{brs}$ & 16 & $3.25 \mathrm{~m}$ & $3.42 \mathrm{~d}(6.0)$ \\
$2 \mathrm{a}$ & $2.02 \mathrm{~m}$ & $1.64 \mathrm{dt}(16.2,4.2)$ & 17 & $2.87 \mathrm{brs}$ & $3.47 \mathrm{~s}$ \\
$2 \mathrm{~b}$ & $2.34 \mathrm{~m}$ & $2.38 \mathrm{~d}(16.2)$ & $18 \mathrm{a}$ & $3.55 \mathrm{~d}(8.7)$ & 3.43 (overlapped) \\
3 & $3.75 \mathrm{dd}(8.2,5)$ & $4.29 \mathrm{brd}(4.2)$ & $18 \mathrm{~b}$ & $3.61 \mathrm{~d}(8.7)$ & $3.59 \mathrm{~d}(7.8)$ \\
4 & - & - & $19 \mathrm{a}$ & $2.50 \mathrm{~m}$ & $3.45 \mathrm{~d}(12.0)$ \\
5 & $2.10 \mathrm{~m}$ & $2.60 \mathrm{~d}(6.6)$ & $19 \mathrm{~b}$ & $2.73 \mathrm{~m}$ & $3.65 \mathrm{~d}(12.0)$ \\
6 & $4.03 \mathrm{~d}(7.0)$ & $4.26 \mathrm{dd}(6.6,1.8)$ & 20 & $2.38 \mathrm{~s}$ & $3.15 \mathrm{~s}$ \\
7 & $2.85 \mathrm{brs}$ & $3.12 \mathrm{~d}(1.8)$ & $1^{\prime}$ & - & - \\
8 & - & - & $2^{\prime} / 6^{\prime}$ & $8.01 \mathrm{~d}(7.4)$ & $8.06 \mathrm{dd}(7.8,1.2)$ \\
9 & $2.58 \mathrm{t}(6.0)$ & $2.63 \mathrm{dd}(7.2,5.4)$ & $3^{\prime} / 5^{\prime}$ & $7.43 \mathrm{t}(7.4)$ & $7.53 \mathrm{t} \mathrm{(7.8)}$ \\
10 & $2.07 \mathrm{~m}$ & $2.56 \mathrm{~m}$ & $4^{\prime}$ & $7.54 \mathrm{t}(7.5)$ & $7.65 \mathrm{~m}$ \\
11 & - & - & $7^{\prime}$ & - & - \\
$12 \mathrm{a}$ & $2.07 \mathrm{~m}$ & $1.93 \mathrm{~m}$ & $\mathrm{OCH}_{3}-1$ & $3.28 \mathrm{~s}$ & $3.41 \mathrm{~s}$ \\
$12 \mathrm{~b}$ & $2.70 \mathrm{~m}$ & $2.33 \mathrm{~m}$ & $\mathrm{OCH}_{3}-6$ & $3.28 \mathrm{~s}$ & $3.37 \mathrm{~s}$ \\
13 & - & - & $\mathrm{OCH}_{3}-8$ & $3.12 \mathrm{~s}$ & $3.18 \mathrm{~s}$ \\
14 & $4.82 \mathrm{~d}(5.1)$ & $4.87 \mathrm{~d}(5.4)$ & $\mathrm{OCH}_{3}-16$ & $3.71 \mathrm{~s}$ & $3.70 \mathrm{~s}$ \\
15 & $4.52 \mathrm{~d}(6.0)$ & $4.70 \mathrm{~d}(6.0)$ & $\mathrm{OCH}_{3}-18$ & $3.30 \mathrm{~s}$ & $3.32 \mathrm{~s}$ \\
\hline
\end{tabular}


Monoester-type $\mathrm{C}_{19}$-diterpenoid alkaloids

Table 2. ${ }^{13} \mathrm{C}$ NMR data for compound $\mathbf{1}$ (150 MHz) and hokbusine A [16]

\begin{tabular}{cccccc}
\hline No. & hokbusine A & $\mathbf{1}$ & No. & hokbusine A & $\mathbf{1}$ \\
\hline 1 & 82.7 & 80.8 & 16 & 93.4 & 94.5 \\
2 & 34.0 & 30.3 & 17 & 62.6 & 67.9 \\
3 & 71.7 & 70.2 & 18 & 76.7 & 77.4 \\
4 & 43.7 & 44.2 & 19 & 50.1 & 52.2 \\
5 & 45.8 & 42.5 & 20 & 42.8 & 42.0 \\
6 & 83.3 & 82.8 & $1^{\prime}$ & 56.5 & 131.1 \\
7 & 41.6 & 43.4 & $2^{\prime} / 6^{\prime}$ & 130.0 & 130.4 \\
8 & 82.5 & 83.5 & $3^{\prime} / 5^{\prime}$ & 128.7 & 129.3 \\
9 & 45.4 & 45.0 & $4^{\prime}$ & 133.3 & 133,9 \\
10 & 41.9 & 40.9 & $7^{\prime}$ & 166.4 & 166.3 \\
11 & 50.7 & 51.7 & $\mathrm{OCH}_{3}-1$ & 56.5 & 55.5 \\
12 & 36.4 & 36.6 & $\mathrm{OCH}_{3}-6$ & 58.8 & 59.1 \\
13 & 75.1 & 75.4 & $\mathrm{OCH}_{3}-8$ & 50.0 & 50.3 \\
14 & 79.7 & 80.0 & $\mathrm{OCH}_{3}-16$ & 62.9 & 62.5 \\
15 & 77.8 & 76.8 & $\mathrm{OCH}_{3}-18$ & 59.4 & 59.3 \\
\hline
\end{tabular}

\subsection{Cardiotoxicity On H9c2 Cells}

The cardiotoxicity of seven isolated monoester-type $\mathrm{C}_{19}$-diterpenoid alkaloids (1-7) were evaluated using H9c2 cells and zebrafish embryos. As shown in Figure 5, all the alkaloids exhibited significant toxicity in $\mathrm{H} 9 \mathrm{c} 2$ cells at concentrations of $1.56,3.125,6.25,12.5,25$, and $50 \mu \mathrm{M}$. Among them, compounds 2 and $\mathbf{6}$ showed the strongest toxicity in a dose-dependent manner. Particularly, the survival rates of compounds 2 and 6 at $50 \mu \mathrm{M}$ decreased to $46.73 \pm 3.81 \%$ and $48.80 \pm 4.54 \%$, respectively. Comparison of compounds $\mathbf{2}$ and $\mathbf{3}$ suggested that the monoester-type $\mathrm{C}_{19}$-diterpenoid alkaloids with a $\mathrm{N}-\mathrm{CH}_{3}$ group had stronger cytotoxicity than those with a $\mathrm{N}-\mathrm{CH}_{2} \mathrm{CH}_{3}$ group. When compared with compound 4, introduction of an $\alpha-\mathrm{OH}$ group at $\mathrm{C}-15$ in compound 6 improved the cytotoxicity. In addition, replacement of a benzoyl group (4) by a cinnamyl group (7) resulted in loss of the cytotoxicity. Therefore, it can be inferred that the alkyl group at $\mathrm{N}$, the acyloxy group at $\mathrm{C}-14$, and the hydroxy group at $\mathrm{C}-15$ have significant effects on the cytotoxicity of monoester-type $\mathrm{C}_{19}$ diterpenoid alkaloids in $\mathrm{H} 9 \mathrm{c} 2$ cells. 

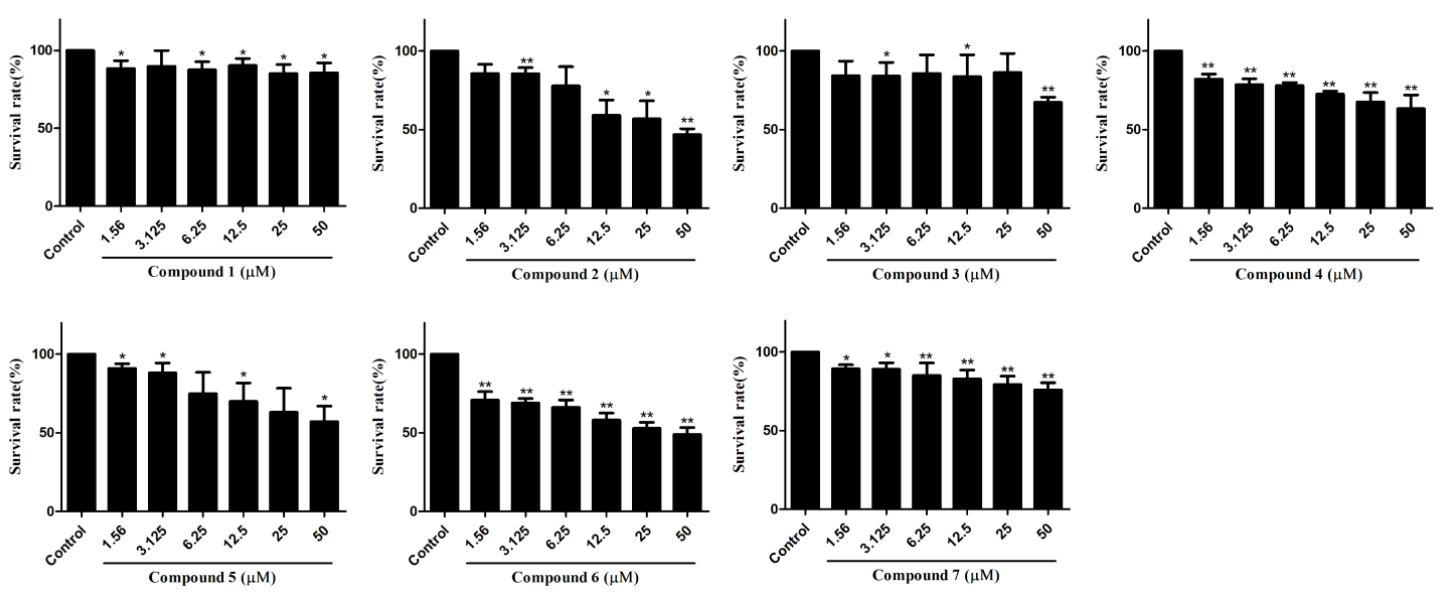

Figure 5. Cytotoxic effects of compounds 1-7 in H9c2 cells. Results are showed as the mean \pm SD for three individual experiments. $* P<0.05$, $* * P<0.01$ vs the control group.

\subsection{Cardiotoxicity On Zebrafish Embryos}

After treatment with the isolated monoester-type $\mathrm{C}_{19}$-diterpenoid alkaloids at $6.25,12.5,25$, and $50 \mu \mathrm{M}$, the zebrafish embryos developed abnormally with symptoms of cardiotoxicity. As shown in Figure 6, the representative toxic compounds ( 2 and $\mathbf{6})$ had notable cardiotoxic effects on the heart morphology of zebrafish, mainly including the serious pericardial edema and yolk sac edema. Furthermore, Figure 7 showed that the malformation rates of zebrafish treated with the monoester-type $\mathrm{C}_{19}$-diterpenoid alkaloids increased significantly, especially the malformation rates of zebrafish treated with compounds 2 and 6 at 25 and $50 \mu \mathrm{M}$. In addition to the malformation rates, the heart rates of zebrafish were also affected by the above alkaloids (Figure 8). Particularly, the average heart rate of the control zebrafish embryos was $164.5 \pm 3.42$ beats $/ \mathrm{min}$, while the average heart rates increased to $179.5 \pm 1.92$ (compound 1), $192.5 \pm 7.72$ (compound 2), $173.5 \pm 4.44$ (compound 3), $172.5 \pm 3.42$ (compound 5), and $188 \pm 8.64$ beats/min (compound 6) at $50 \mu \mathrm{M}$. These results indicated that the isolated monoester-type $\mathrm{C}_{19}$-diterpenoid alkaloids had cardiotoxic effects on $\mathrm{H} 9 \mathrm{c} 2$ cells and zebrafish embryos.

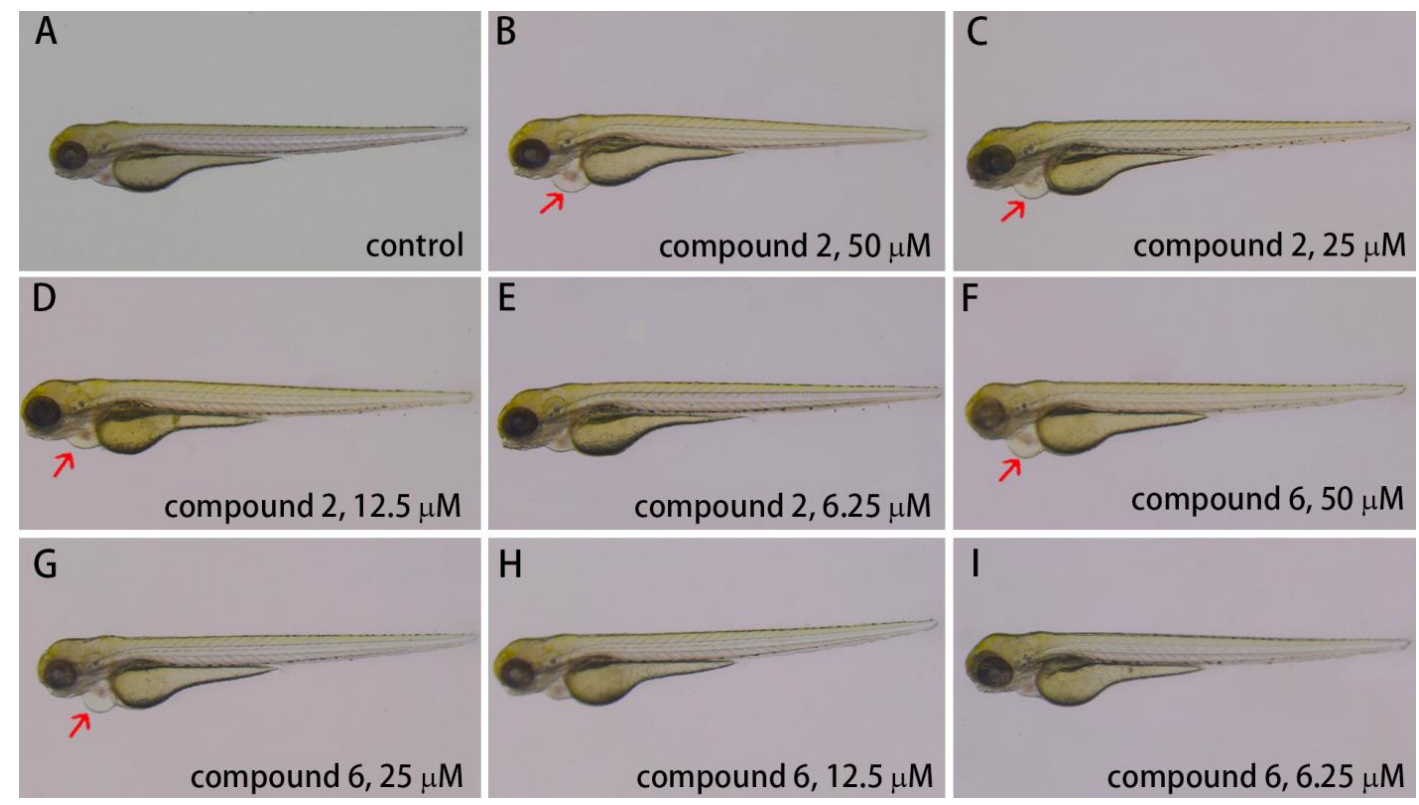

Figure 6. Effects of compounds $\mathbf{2}$ and $\mathbf{6}$ on the heart morphology of zebrafish. 


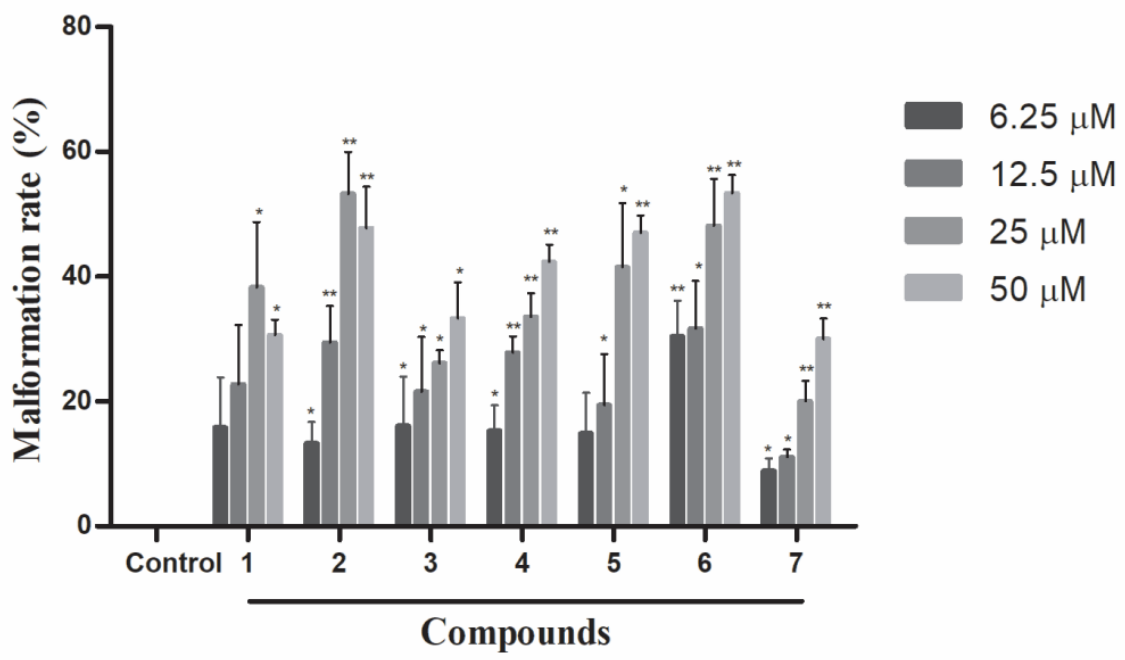

Figure 7. Effects of compounds 1-7 on malformation rates of zebrafish. Results are presented as the mean \pm SD for three individual experiments. $* P<0.05, * * P<0.01 \mathrm{vs}$ the control group.

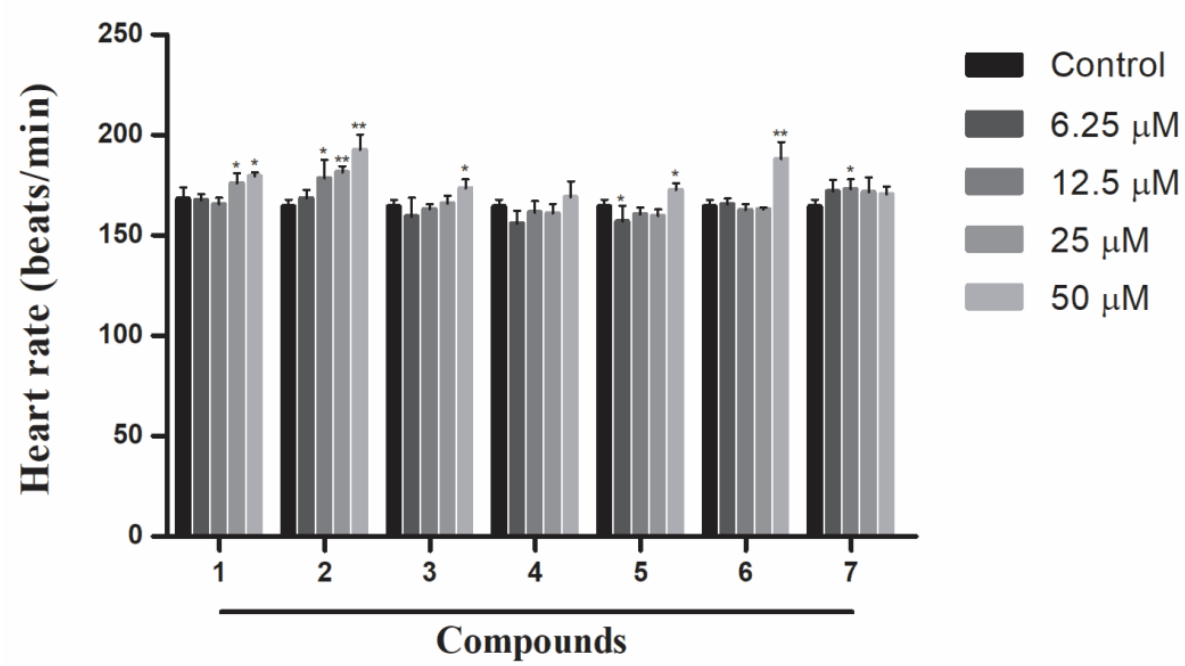

Figure 8. Effects of compounds 1-7 on heart rates of zebrafish. Results are presented as the mean \pm SD for three individual experiments. $* P<0.05, * * P<0.01$ vs the control group.

\section{Conclusion}

So far, more than $80 \mathrm{C}_{19}$-diterpenoid alkaloids have been isolated from Fuzi [4,14,25]. It is worth noting that the substituent group at C-1 is mostly $\alpha$-oriented [4,26,27]. However, in this study, we obtained a monoester-type $\mathrm{C}_{19}$-diterpenoid alkaloid possessing an unusual $1 \beta$-methoxy group (1). In addition, researchers have increasingly focused on the cardiotoxicity of diester-type $\mathrm{C}_{19}$-diterpenoid alkaloids in Fuzi, but few studies have looked at the cardiotoxicity of monoester-type $\mathrm{C}_{19}$-diterpenoid alkaloids. This study demonstrated that all the isolated monoester-type $\mathrm{C}_{19}$-diterpenoid alkaloids had cardiotoxic effects on $\mathrm{H} 9 \mathrm{c} 2$ cells and zebrafish embryos. Thus, this study has greatly improved the understanding of the cardiotoxicity of Fuzi. 


\section{Acknowledgments}

This study was funded by the National Natural Science Foundation of China (NNSFC; Nos. 81630101, 81891012, and 81891010), the Sichuan Science and Technology Program (Grant No. 2018JZ0081), and the "Xinglin Scholar" Plan of Chengdu University of Traditional Chinese Medicine (Grant Nos. YXRC2018005, BSH2019028, and QNXZ2019030).

\section{Supporting Information}

Supporting information accompanies this paper on http://www.acgpubs.org/journal/records-ofnatural-products

\section{ORCID}

Qiao Lin: 0000-0002-8828-7741

Chunwang Meng: 0000-0002-2119-7039

Jie Liu: 0000-0003-4174-2193

Qinmei Zhou: 0000-0002-5068-4725

Xingjie Ding: 0000-0002-8532-0649

Lulin Miao: 0000-0002-8562-9718

Xiaoya Wang: 0000-0002-9742-0313

Ou Dai: 0000-0001-6120-1138

Cheng Peng: 0000-0003-3303-906X

\section{Author Contribution}

\#Q. Lin. and C. W. Meng contributed equally.

\section{References}

[1] Q. W. Huang, Z. Y. Zhou, J. Wang and R. H. Liu (2011). Studies of traditional Chinese pharmaeutical processe for Aconitum Carmichalii Debx in medical history, Chin. J. Exp. Tradit. Med. Form. 17, 269271.

[2] S. H. Dong, J. Meng, M. H. Wu, Z. G. Ma, H. Cao and Y. Zhang (2020). Herbalogical study of Aconiti lateralis Radix praeparata (Fuzi), Chin. J. Chin. Mater. Med. 45, 5567-5575.

[3] J. L. Zhang, Z. J. Zeng, B. Zhang and S. Q. Yu (2014). Analysis clinical adverse reactions of Aconiti lateralis Radix praeparata, Chin. J. Exp. Tradit. Med. Form. 20, 228-231.

[4] G. Zhou, L. Tang, X. Zhou, T. Wang, Z. Kou and Z. Wang (2015). A review on phytochemistry and pharmacological activities of the processed lateral root of Aconitum carmichaelii Debeaux, J. Ethnopharmacol. 160, 173-193.

[5] D. D. Yang, Q. Zhang and F. C. Liu (2019). Effects of licorice concentrated decoction in treatment of arrhythmia caused by monkshood poisoning: A retrospective clinical study, Chin. J. Tradit. Chin. Med. Pharm. 34, 417-419.

[6] J. He, P. Wu, Y. Dong and R. Gao (2019). Adverse reactions analysis of Aconiti Lateralis Radix Praeparata and mechanism prediction of cardiac toxicity by network pharmacology, Chin. J. Chin. Mater. Med. 44, 1010-1018.

[7] M. Yang, X. Ji and Z. Zuo (2018). Relationships between the toxicities of Radix Aconiti lateralis preparata (Fuzi) and the toxicokinetics of its main diester-diterpenoid alkaloids, Toxins 10, 391.

[8] Z. T. Zhang, X. X. Jian, J. Y. Ding, H. Y. Deng, R. B. Chao, Q. H. Chen, D. L. Chen and F. P. Wang (2015). Further studies on structure-cardiac activity relationships of diterpenoid alkaloids, Nat. Prod. Commun. 10, 2074-2085.

[9] X. Chen, Y. Cao, H. Zhang, Z. Zhu, M. Liu, H. Liu, X. Ding, Z. Hong, W. Li, D. Lv, L. Wang, X. Zhuo, J. Zhang, X. Q. Xie and Y. Chai (2014). Comparative normal/failing rat myocardium cell membrane chromatographic analysis system for screening specific components that counteract doxorubicininduced heart failure from Acontium carmichaeli, Anal. Chem. 86, 4748-4757. 


\section{Monoester-type $\mathrm{C}_{19}$-diterpenoid alkaloids}

[10] X. Y. Wang, Q. M. Zhou, L. Guo, O. Dai, C. W. Meng, L. L. Miao, J. Liu, Q. Lin, C. Peng and L. Xiong (2021). Cardioprotective effects and concentration-response relationship of aminoalcohol-diterpenoid alkaloids from Aconitum carmichaelii, Fitoterapia 149, 104822.

[11] F. Liu, X. Han, N. Li, K. Liu and W. Kang (2019). Aconitum alkaloids induce cardiotoxicity and apoptosis in embryonic zebrafish by influencing the expression of cardiovascular relative genes, Toxicol. Lett. 305, 10-18.

[12] C. Bi, T. Zhang, Y. Li, H. Zhao, P. Zhang, Y. Wang, Y. Xu, K. Gu, Y. Liu, J. Yu, W. Qi, S. Fan, Y. Li and Y. Zhang (2020). A proteomics- and metabolomics-based study revealed that disorder of palmitic acid metabolism by aconitine induces cardiac injury, Chem. Res. Toxicol. 33, 3031-3040.

[13] M. Li, X. Xie, H. Chen, Q. Xiong, R. Tong, C. Peng and F. Peng (2020). Aconitine induces cardiotoxicity through regulation of calcium signaling pathway in zebrafish embryos and in $\mathrm{H} 9 \mathrm{c} 2$ cells, J. Appl. Toxicol. 40, 780-793.

[14] X. Zong, X. Yan, J. L. Wu, Z. Liu, H. Zhou, N. Li and L. Liu (2019). Potentially cardiotoxic diterpenoid alkaloids from the roots of Aconitum carmichaelii, J. Nat. Prod. 82, 980-989.

[15] M. Westerfield (2000). The Zebrafish Book. A guide for the laboratory use of zebrafish (Danio Rerio), 4th ed. University of Oregon Press, Eugene.

[16] D. H. Wei, F. Wang, B. Song, J. C. Cui, X. M. Song and Z. G. Yue (2015). Diterpenoid alkaloids from Aconitum Penduli Radix and their bioactivities, Chin. J. Exp. Tradit. Med. Form. 21, 48-52.

[17] M. W. Lodewyk, M. R. Siebert and D. J. Tantillo (2012). Computational prediction of ${ }^{1} \mathrm{H}$ and ${ }^{13} \mathrm{C}$ chemical shifts: A useful tool for natural product, mechanistic, and synthetic organic chemistry, Chem. Rev. 112, 1839-1862.

[18] N. Grimblat, M. M. Zanardi and A. M. Sarotti (2015). Beyond DP4: an improved probability for the stereochemical assignment of isomeric compounds using quantum chemical calculations of NMR shifts, J. Org. Chem. 80, 12526-12534.

[19] K. Ishimi, M. Makino, Y. Asada, Y. Ichinohe and Y. Fujimoto (2006). Norditerpenoid alkaloids from Aconitum manshuricum, J. Nat. Med. 60, 255-257.

[20] Z. Li, G. Lu, D. Chen and F. Wang (1997). Chemical study on the alkaloids of "Cao Wu", Nat. Prod. Res. Dev. 9, 9-14.

[21] K. Wada, H. Bando, T. Mori, R. Wada, Y. Kanaiwa and T. Amiya (1985). Studies on the constituents of Aconitum species. III.1) on the components of Aconitum subcuneatum NAKAI, Chem. Pharm. Bull. 33, 3661.

[22] X. Qin, S. Yang, Y. Zhao, Y. Gao, F. Ren, D. Zhang and F. Wang (2015). Five new C 19 -diterpenoid alkaloids from Aconitum carmichaelii, Phytochem. Lett. 13, 390-393.

[23] B. Jiang, S. Lin, C. Zhu, S. Wang, Y. Wang, M. Chen, J. Zhang, J. Hu, N. Chen, Y. Yang and J. Shi (2012). Diterpenoid alkaloids from the lateral root of Aconitum carmichaelii, J. Nat. Prod. 75, 1145 1159.

[24] S. H. Shim, J. S. Kim and S. S. Kang (2003). Norditerpenoid alkaloids from the processed tubers of Aconitum carmichaeli, Chem. Pharm. Bull. 51, 999-1002.

[25] Y. Li, F. Gao, J. F. Zhang and X. L. Zhou (2018). Four new diterpenoid alkaloids from the roots of Aconitum carmichaelii, Chem. Biodivers. 15, e1800147.

[26] M. Tang, L. C. Zhao, M. Xu, J. Leng, N. Tang, Z. Y. Hu and Q. H. Zhang (2017). Chemical constituents and pharmacological activities of Aconiti ateralis Radix praeparata, Guihaia 37, 1614-1627.

[27] X. C. Zhang, Q. G. Zheng, J. H. Yang, R. Rong and Y. Yang (2020). Research progress on structure and activity of $\mathrm{C}_{19}$ diterpenoid alkaloids from Aconiti lateralis Radix praeparata, Chin. Tradit. Herbal Drugs 51, 531-541.

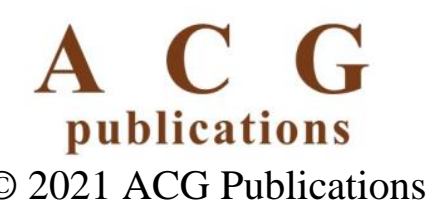

